\title{
Yo-yo vertical movements suggest a foraging strategy for tiger sharks Galeocerdo cuvier
}

\author{
Itsumi Nakamura $^{1, *}$, Yuuki Y. Watanabe ${ }^{2}$, Yannis P. Papastamatiou ${ }^{3}$, \\ Katsufumi Sato ${ }^{1}$, Carl G. Meyer ${ }^{4}$ \\ ${ }^{1}$ International Coastal Research Center, Atmosphere and Ocean Research Institute, University of Tokyo, 2-106-1 Akahama, \\ Otsuchi, Iwate 028-1102, Japan \\ ${ }^{2}$ National Institute of Polar Research, 10-3 Midori-cho, Tachikawa, Tokyo 190-8518, Japan \\ ${ }^{3}$ Florida Museum of Natural History, University of Florida, 280 Dickinson Hall, Museum Road, Gainesville, Florida 32611, USA \\ ${ }^{4}$ Hawaii Institute of Marine Biology, University of Hawaii at Manoa, PO Box 1346, Kaneohe, Hawaii 96744, USA
}

\begin{abstract}
Many pelagic fishes exhibit 'yo-yo' diving behavior, which may serve several possible functions, including energy conservation, prey searching and navigation. We deployed accelerometers and digital still cameras on 4 free-ranging tiger sharks Galeocerdo cuvier, to test whether their vertical movements are most consistent with energy conservation or prey searching. All sharks swam continuously, with frequent vertical movements through the water column at mean swimming speeds of 0.5 to $0.9 \mathrm{~m} \mathrm{~s}^{-1}$. Tail-beating was continuous except for sporadic, powerless gliding during descents (from 0 to $18 \%$ of total descent time). At a given tailbeat frequency, swimming speeds were lower during ascent than descent (consistent with negative buoyancy). Burst swimming events, which might represent prey pursuits, were observed during all phases of vertical movements. Camera images showed a variety of potential prey and the possible capture of a unicornfish. Collectively, results suggest that yo-yo diving by tiger sharks is not primarily for energy conservation, but probably represents an effective search strategy for locating prey throughout the water column.
\end{abstract}

KEY WORDS: Tiger shark • Marine top predator • Swimming behavior • Swim speed . Stroke frequency $\cdot$ Foraging $\cdot$ Bio-logging $\cdot$ Data logger

Resale or republication not permitted without written consent of the publisher

\section{INTRODUCTION}

Time-depth recorders and pressure-sensitive transmitters have shown that many pelagic fishes, including tunas and sharks, conduct repetitive, oscillating vertical movements commonly referred to as 'yo-yo' dives (Block et al. 2001, Carey \& Scharold 1990, Holland et al. 1992). Theories postulated to explain this widespread behavior include behavioral thermoregulation, navigation using magnetoreception, energy conservation, and foraging (Carey \& Scharold 1990, Holland et al. 1990, 1992, Klimley et al. 2002). These functions are not mutually exclusive, and their relative importance may differ both inter- and intra-specifically. Nevertheless, some functions of yo-yo diving in pelagic fishes might be generally more important than others.

Previous studies examining the possible function of the vertical movements were based solely on swim- ming depth data, which precludes us from further narrowing the possibilities. Weihs (1973) predicted that negatively buoyant fishes, such as tuna and sharks, could theoretically reduce the energetic cost of travel by nearly $50 \%$ by alternating between powerless gliding during descent and active swimming during ascent. Based on swimming depth profiles, Holland et al. (1990) suggested that tuna save energy through vertical movements, whereas Carey \& Scharold (1990) concluded that vertical movements in pelagic sharks are unrelated to energy saving. To verify the energy conservation hypothesis, it is necessary to further quantify detailed swimming behavior (viz. tailbeat activity and pitch angle). A recent study using an animal-borne video camera (Heithaus et al. 2002) showed that tiger sharks do not glide during descent, but this study was conducted in very shallow water $(<15 \mathrm{~m})$, precluding the possibility of large vertical movements 
shown by this species in pelagic environments (Holland et al. 1999). Furthermore, forward-facing video cameras do not permit a detailed analysis of swimming behavior. Fortunately, recently developed accelerometers allow very fine-scale measurement of animal body movements (Yoda et al. 2001).

Vertical movements by pelagic fishes might also be primarily related to foraging. For example, Sims et al. (2008) showed that the frequency distribution of vertical movements by pelagic predators agrees with the theoretical optimum for locating patchily distributed prey. However, until recently, it has proven extremely difficult to empirically quantify foraging in pelagic fishes. Fortunately the development of animal-borne image recorders has provided useful new tools for obtaining visual information about foraging behaviors (Marshall 1998, Heithaus et al. 2001, 2002, Watanabe et al. 2003, 2004). The combination of animal-borne image recorders with accelerometers offers a promising new method for evaluating the possible relationship between vertical movements and foraging behavior.

The tiger shark Galeocerdo cuvier is a large (up to $5.5 \mathrm{~m}$ total length), wide-ranging obligate swimmer with a broad diet (Lowe et al. 1996, Holland et al. 1999, Meyer et al. 2009), and previous studies have revealed that this species exhibits yo-yo diving behavior (Holland et al. 1999, Heithaus et al. 2002). In the present study, we deployed accelerometers and digital still cameras on tiger sharks to quantify their fine-scale swimming behavior and to determine whether foraging occurred during vertical movements. Our goal was to ascertain whether yo-yo diving in tiger sharks most closely resembled theoretical energy-saving or effective prey search strategies.

\section{MATERIALS AND METHODS}

Deployment of instruments. Tiger sharks were captured using demersal long-lines set off the west coast of Hawaii Island $\left(19.70^{\circ} \mathrm{N}, 156.00^{\circ} \mathrm{W}\right)$. Lines baited with fish scraps were set over night in water depths of 30 to $60 \mathrm{~m}$ and were retrieved the next morning (see Holland et al. 1999 for additional details of longline fishing methods). Captured sharks were brought alongside a $6 \mathrm{~m}$ boat, where they were tail-roped, inverted to induce tonic immobility and measured. Measurements taken were total length (TL), precaudal length and maximum girth (Table 1).

To quantify swimming performance and behavior, we used an accelerometer package that recorded swimming speed, depth, temperature (at 1 s intervals) and tri-axial acceleration (at 1/32 s intervals, $32 \mathrm{~Hz}$ ). The accelerometer used was a W1000-PD3GT (22 mm diameter, $123 \mathrm{~mm}$ length, $90 \mathrm{~g}$ in air; Little Leonardo). Speed data, which were obtained from a propeller situated at the front of the cylindrical accelerometer, were recorded as the number of propeller rotations per second. This device has already been used to accurately record swimming speed from a wide range of animals (Sato et al. 2007, Watanabe et al. 2010). Propeller rotations were converted to $\mathrm{m} \mathrm{s}^{-1}$ using a regression equation derived from empirical calibration tests. During calibration, the accelerometer was towed from $50 \mathrm{~m}$ depth to the surface $(0 \mathrm{~m})$ at 8 different speeds using an electric reel on a vessel, and the duration of each tow was measured using a stopwatch. We then compared the mean number of propeller rotations per tow, and calculated speed (50 m per towing time). The linear regression line was obtained with $\mathrm{r}^{2}=0.99$ $(n=8)$. Acceleration data were recorded as a 12-bit number (from 0 to 4095) and converted to $\mathrm{m} \mathrm{s}^{-2}$ on the basis of acceleration due to gravity $\left(9.8 \mathrm{~m} \mathrm{~s}^{-2}\right)$. During calibration, the accelerometer was positioned to record the value of gravity acceleration in all 3 axes. We also used an animal-borne digital camera DSL380-VDTII (22 mm diameter, $132 \mathrm{~mm}$ length, $83 \mathrm{~g}$ in air; Little Leonardo), which captured still images (1 MPx) at $4 \mathrm{~s}$ intervals, and recorded depth and temperature at $1 \mathrm{~s}$ intervals. The accelerometer and the digital camera were attached to a float equipped with a VHF transmitter and timed-release mechanism (Watanabe et al. 2004). We deployed accelerometer packages on 4 individuals (TL from 328 to $393 \mathrm{~cm}$ ): accelerometer only on sharks \#1 and \#2, and both accelerometer and digital camera on sharks \#3 and \#4. Total device weights in air

Table 1. Galeocerdo cuvier. Summary of physical and swimming performance data for 4 instrumented tiger sharks and 1 dead shark. Estimated body mass of instrumented sharks was calculated from total length. Mass of the dead shark was measured empirically

\begin{tabular}{|lccccccc|}
\hline $\begin{array}{l}\text { Shark } \\
\text { ID }\end{array}$ & Sex & $\begin{array}{c}\text { Total } \\
\text { length }(\mathrm{m})\end{array}$ & $\begin{array}{c}\text { Pre-caudal } \\
\text { length }(\mathrm{m})\end{array}$ & $\begin{array}{c}\text { Estimated body } \\
\text { mass }(\mathrm{kg})\end{array}$ & $\begin{array}{c}\text { Girth } \\
(\mathrm{m})\end{array}$ & $\begin{array}{c}\text { Water temperature }\left({ }^{\circ} \mathrm{C}\right) \\
\text { Avg. } \pm \text { SD (min.-max.) }\end{array}$ & $\begin{array}{c}\left.\text { Swimming speed (m s }{ }^{-1}\right) \\
\text { Avg. } \pm \text { SD }(\mathrm{min} .-\mathrm{max} .)\end{array}$ \\
\hline$\# 1$ & Female & 3.93 & 2.87 & 356 & 1.76 & $26.5 \pm 0.9(21.6-27.6)$ & $0.72 \pm 0.17(0.25-2.41)$ \\
$\# 2$ & Female & 3.76 & 2.80 & 309 & 1.73 & $26.3 \pm 0.4(24.6-27.4)$ & $0.57 \pm 0.18(0.08-1.26)$ \\
$\# 3$ & Male & 3.30 & 2.45 & 202 & 1.55 & $26.2 \pm 0.2(24.1-26.9)$ & $0.54 \pm 0.19(0.13-1.46)$ \\
$\# 4$ & Female & 3.28 & 2.33 & 198 & 1.47 & $23.8 \pm 2.0(14.6-26.9)$ & $0.92 \pm 0.16(0.40-1.88)$ \\
Dead & Male & 2.80 & 2.02 & 101 & 1.00 & & \\
\hline
\end{tabular}


were $188 \mathrm{~g}$ (accelerometer only) and $311 \mathrm{~g}$ (accelerometer and camera); their buoyancies were $54 \mathrm{~g}$-f and $76 \mathrm{~g}-\mathrm{f}$, respectively, in seawater. Total masses of the devices were less than $0.2 \%$ of the shark's estimated mass. The devices were attached to the dorsal fin of each shark by plastic cable ties secured through 2 small holes drilled through the fin (Fig. 1). To facilitate active tracking, each shark was also surgically implanted with a V16 acoustic pinger (51 to $84 \mathrm{kHz}$, $16 \mathrm{~mm}$ diameter, $94 \mathrm{~mm}$ length, $14 \mathrm{~g}$ weight in water; Vemco) through a small incision in the abdominal wall, which was then closed using a single suture. After release, we actively tracked each shark using a $6 \mathrm{~m}$ boat equipped with an onboard VR100 receiver and VH110 directional hydrophone (both Vemco). The receiver recorded the GPS position of the tracking vessel every second. After $6 \mathrm{~h}$, a pre-programmed release timer caused the accelerometer package to detach and float to the surface, where the VHF transmitter enabled us to locate and retrieve the devices. Procedures were approved by the ethics committee at the University of Hawaii (Institutional Animal Case and Use Comittee Protocol \#05-053-4).

As body density of aquatic animals affects swimming behavior, we empirically measured the body density of a dead tiger shark (TL $2.8 \mathrm{~m}$ ) to confirm that tiger sharks are negatively buoyant in seawater, and to determine the magnitude of that negative buoyancy. The weight in air $\left(F_{\mathrm{a}} \mathrm{kg}-\mathrm{f}\right)$ and apparent weight in seawater $\left(F_{\mathrm{w}} \mathrm{kg}-\mathrm{f}\right)$ were measured using a hanging scale, and total shark density $\rho_{\mathrm{f}}\left(\mathrm{kg} \mathrm{m}^{-3}\right)$ was calculated using the following equation;

$$
F_{\mathrm{w}}=F_{\mathrm{a}}-\frac{\rho_{\mathrm{w}} F_{\mathrm{a}}}{\rho_{\mathrm{f}}}
$$

where $\rho_{\mathrm{w}}\left(\mathrm{kg} \mathrm{m}^{-3}\right)$ is density of seawater $\left(1026 \mathrm{~kg} \mathrm{~m}^{-3}\right)$.

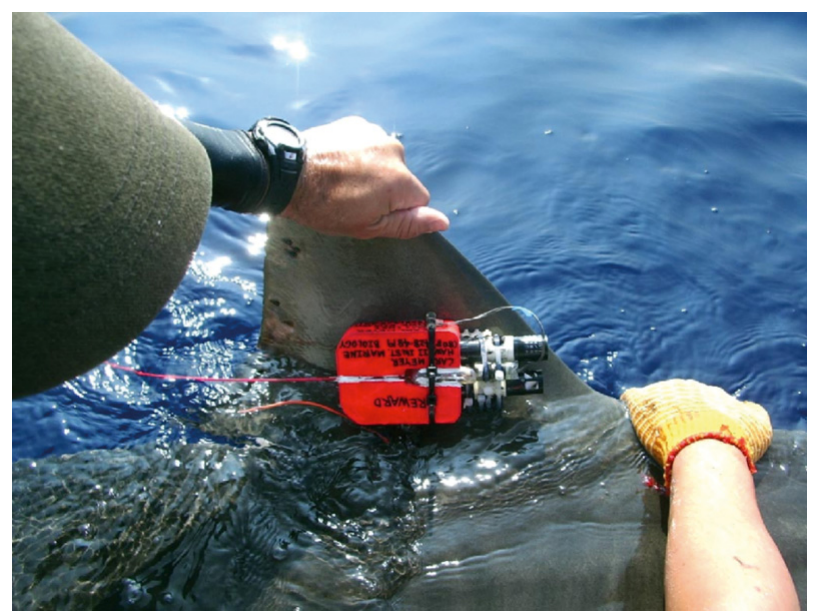

Fig. 1. Data-logger package attached to the dorsal fin of a tiger shark Galeocerdo cuvier
Data analysis. We used Igor Pro Ver.6.04 (WaveMetrics) to analyze shark swimming data. Longitudinal accelerations included both the dynamic movement component and a gravity component caused by pitching. High frequency waves of longitudinal accelerations were caused by dynamic movements such as caudal fin stroking and rapid turning. We separated dynamic and gravity components of acceleration using a $0.01 \mathrm{~Hz}$ low-pass filter (contained within Igor Pro), which removes high frequency waves to reveal the gravity component. We used the gravity component to calculate data logger angles $(\gamma+\Delta \gamma)$. As data loggers were not attached exactly parallel to the longitudinal body axis of each shark, an adjustment angle $\Delta \gamma$ (i.e. the difference between pitch and logger angles) was estimated (Fig. 2). See Sato et al. 2003 for additional details on pitch adjustment protocol.

We used 'Ethographer' software for Igor Pro (Sakamoto et al. 2009) to generate spectrograms for frequency spectrum analysis by wavelet transformation. We generated a spectrogram from lateral acceleration based on the continuous wavelet transformation, and then grouped data into $1 \mathrm{~s}$ intervals. We used the $k$-means algorithm to automatically cluster behavioral spectra by differences in frequency. We set 20 spectra for each individual and assumed the largest peak of each behavioral spectrum to be the tailbeat frequency of the spectrum. We assumed the behavioral spectrum that had no peaks to represent episodes of gliding behavior.

To test whether dive phase (descent or ascent) affected the relationship between swimming speed and tailbeat frequency, we used generalized linear models (GLM) and the Akaike Information Criterion (AIC) to select the most parsimonious model (Wada \& Kashiwagi 1990). We separated behavioral spectra into 3 dive phases (descent, ascent and horizontal) based on the pitch angles of the sharks, assuming pitch angles

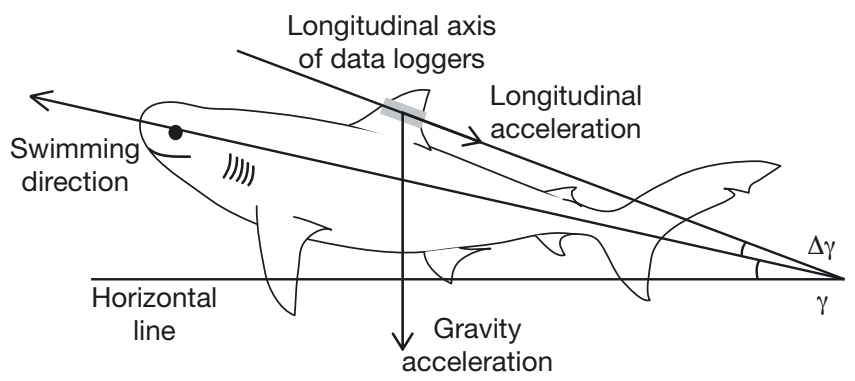

Fig. 2. Schematic diagram of the relationship between longitudinal acceleration and gravity on a shark swimming straight at constant speed. The data logger cannot be attached exactly parallel to the longitudinal body axis of the shark, so the angle of the logger is composed of the body pitch $(\gamma)$ plus the adjustment angle $(\Delta \gamma)$ 
above $5^{\circ}$ to be ascents, below $-5^{\circ}$ to be descents, and intermediate angles to be horizontal swimming. Mean swimming speeds of ascent and descent phases were compared with corresponding tailbeat frequencies. We regarded the distribution of swimming speed as Gaussian, and used the function glm contained in $\mathrm{R}$ ver.2.8.0 (R project) to calculate AIC. We configured 3 models for GLM to test which factor affected swimming speed of each individual. We set swimming speed as a response variable in the model, and tailbeat frequency and index of descent or ascent as explanatory variables, as follows:

$$
\begin{gathered}
\text { Model 1: } V=F \\
\text { Model 2: } V=F+A D, \\
\text { Model 3: } V=F+A D+F \times A D,
\end{gathered}
$$

where $F$ is stroke frequency $(\mathrm{Hz}), V$ is swimming speed $\left(\mathrm{m} \mathrm{s}^{-1}\right)$, and $A D$ is index of ascent or descent.

Increases in speed sometimes occurred during the tracks. We assumed these to be burst swimming events, and examined the images taken during these events to investigate whether sharks were involved in prey chase or capture. Potential prey objects (fishes) in the still images were identified as precisely as possible. Using the images supplied by the animal-borne camera we also visually identified the seabed to determine whether sharks were swimming near it.

\section{RESULTS}

All accelerometer packages were retrieved after their scheduled $6 \mathrm{~h}$ deployments, providing a total of $24 \mathrm{~h}$ of daytime data from 4 sharks. During the deployments, sharks \#1, \#3 and \#4 swam near the coast, where bathymetric depth is less than 500 $\mathrm{m}$, whereas shark \#2 swam offshore into open ocean (Fig. 3).

All sharks exhibited yo-yo diving behavior after release (Fig. 4). Water temperature recorded by the loggers decreased rapidly below 80 to $100 \mathrm{~m}$, indicating the presence of a thermocline around that depth. Sharks \#1, \#2 and \#3 spent the majority of their time $(97 \%, 100 \%$, and $100 \%$ of the tracks, respectively) within the mixed layer (<100 m depth), while shark \#4 spent $48 \%$ of its time below $100 \mathrm{~m}$.

Tailbeat acceleration spectra were divided into descent and ascent phases (Fig. 5). During descents, lateral acceleration exhibited a single peak around $0.4 \mathrm{~Hz}$. This was caused by tailbeats, punctuated by short periods when the shark was gliding with no frequency peaks evident in the spectrogram. During ascents, lateral acceleration spectra showed double frequency peaks: a dominant peak around $0.5 \mathrm{~Hz}$ caused by tailbeating, and a smaller peak around 1.5 Hz which may have been tailbeat harmonics. For a given speed, sharks exhibited lower tailbeat frequency during descent than ascent. Sharks \#1 and \#2 also glided on 95 and 166 occasions, respectively, whereas sharks \#3 and \#4 did not glide (Table 2). Brief gliding occurred during all dive phases, but prolonged (>10 s), powerless gliding resulting from negative buoyancy occurred only during descent (Fig. 4 \& 5).

The relationships between swimming speed and tailbeat frequency were linear $\left(\mathrm{r}^{2}=0.89\right.$ to 0.99$)$ in each individual and during each dive phase (Fig. 6). GLM and AIC selected model 3 for sharks \#1, \#2 and \#3, which includes tailbeat frequency, dive phase and interaction between them, and model 2 for shark \#4, which includes tailbeat frequency and dive phase. All the selected models included the dive phase, indicating that the relationship between swimming speed and tailbeat frequency differed between descent and ascent phases. Sharks also showed burst swimming events (14, 7, 9, and 42 times in sharks \#1, \#2, \#3 and \#4, respectively) during all dive phases (Table 2, Fig. 4).

The weight of the dead shark was $101.5 \mathrm{~kg}-\mathrm{f}$ in air and 1.0 to $1.5 \mathrm{~kg}-\mathrm{f}$ in seawater. The total density of the dead shark was estimated to be 1041 to $1047 \mathrm{~kg} \mathrm{~m}^{-3}$, confirming that tiger sharks are negatively buoyant in seawater (density $=1026 \mathrm{~kg} \mathrm{~m}^{-3}$ ).

The digital camera recorded 4896 and 4904 images throughout the tracks of sharks \#3 and \#4, respectively. The seabed was seen in 253 images (5\% of all images) from shark \#3 and 986 images (20\% of all images) from shark \#4, indicating that shark \#3 occasionally encountered the seabed, and shark \#4 was frequently associ-

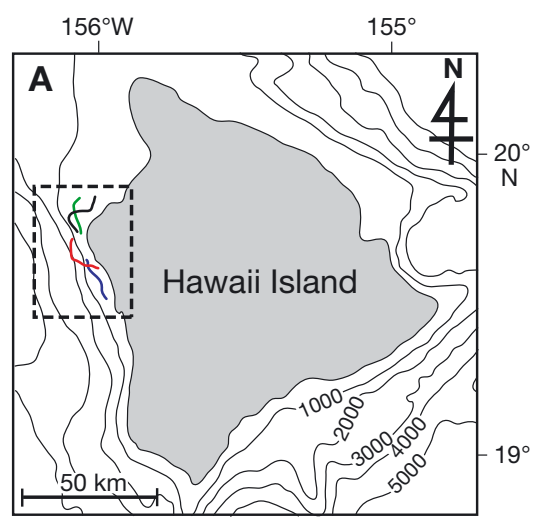

Fig. 3. Galeocerdo cuvier. Active tracks of 4 tiger sharks along the west coast of Hawaii island. Each shark was tracked for $6 \mathrm{~h}$. Circles indicate start of track

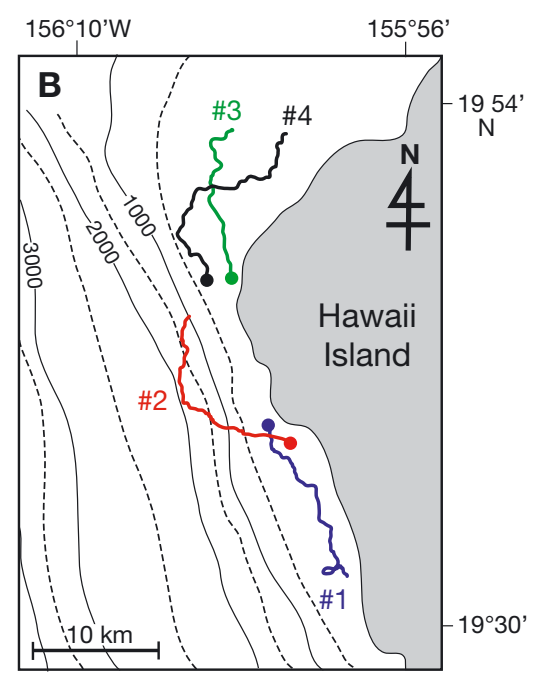



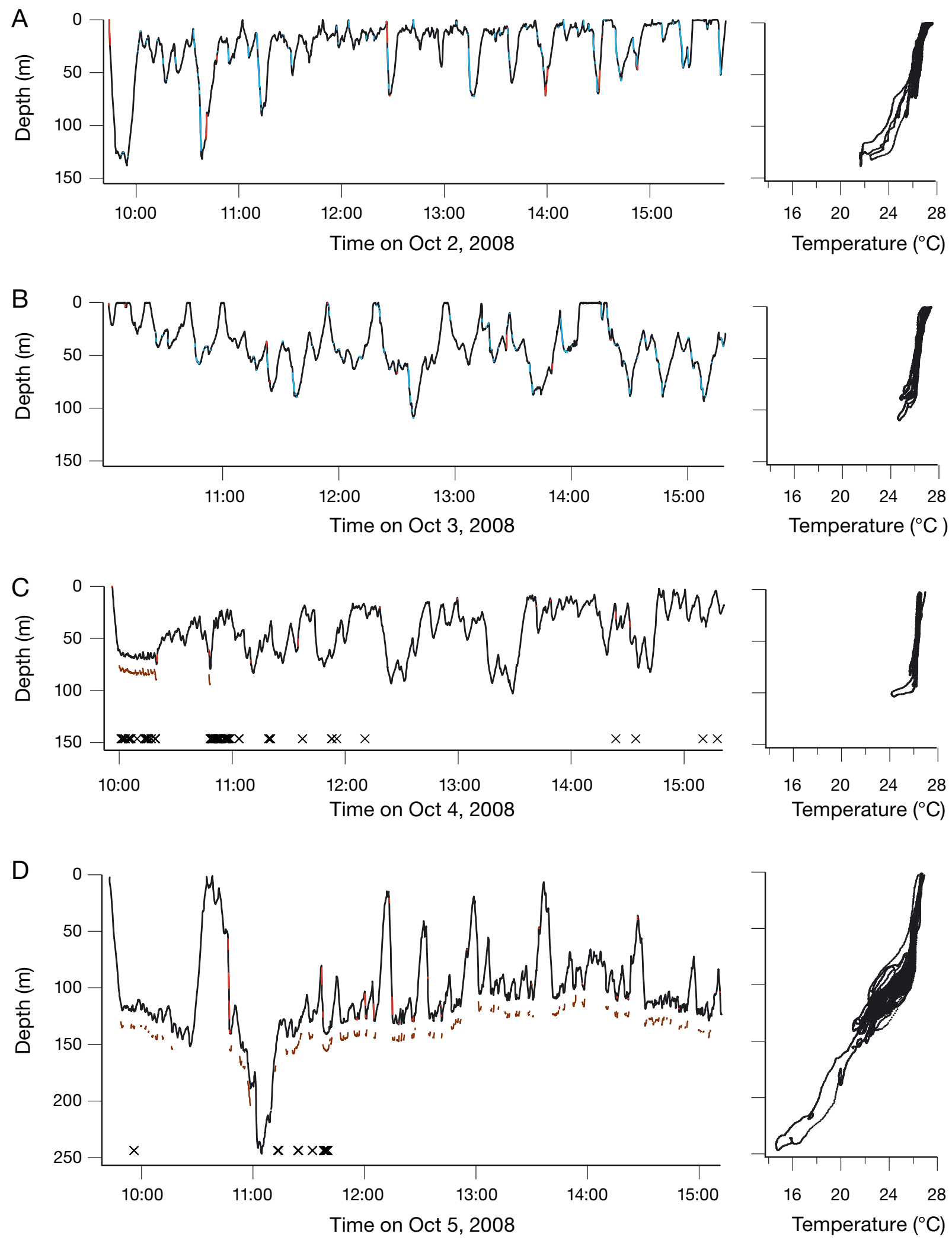

Fig. 4. Galeocerdo cuvier. Depth time-series data and depth-temperature data for each shark. (A) shark \#1, (B) shark \#2, (C) shark \#3, (D) shark \#4. Light blue and red shading in depth profiles indicate the sharks were gliding and burst-swimming, respectively. Brown dots below the depth profiles of sharks \#3 and \#4 indicate the seabed was seen in images recovered from the animal-borne camera. Crosses under the depth profiles of sharks \#3 and \#4 show that potential prey objects were seen in images 


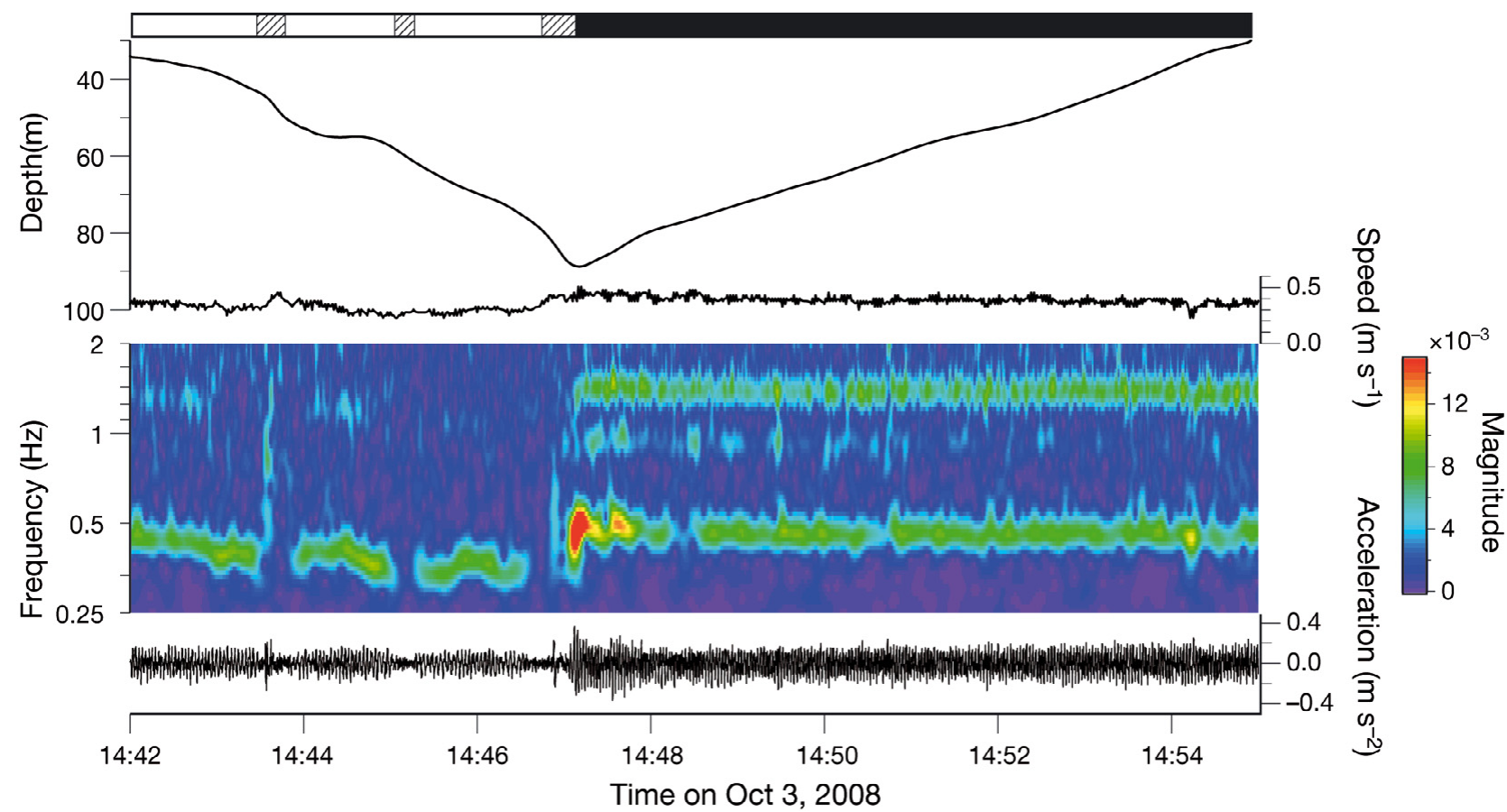

Fig. 5. Galeocerdo cuvier. Spectrogram of one dive obtained from shark \#2. Bar above depth profile-white: descent stroking phase, hatched: gliding phase, black: ascent stroking phase. During the descent, acceleration had a frequency of $0.4 \mathrm{~Hz}$ punctuated by short periods when the shark was gliding with no frequency peaks evident in the spectrogram. During the ascent, acceleration had a higher frequency peak of $0.5 \mathrm{~Hz}$, with another peak at $1.5 \mathrm{~Hz}$ (possibly a harmonic artifact of the dominant frequency)

Table 2. Galeocerdo cuvier. Summary of gliding and burst events

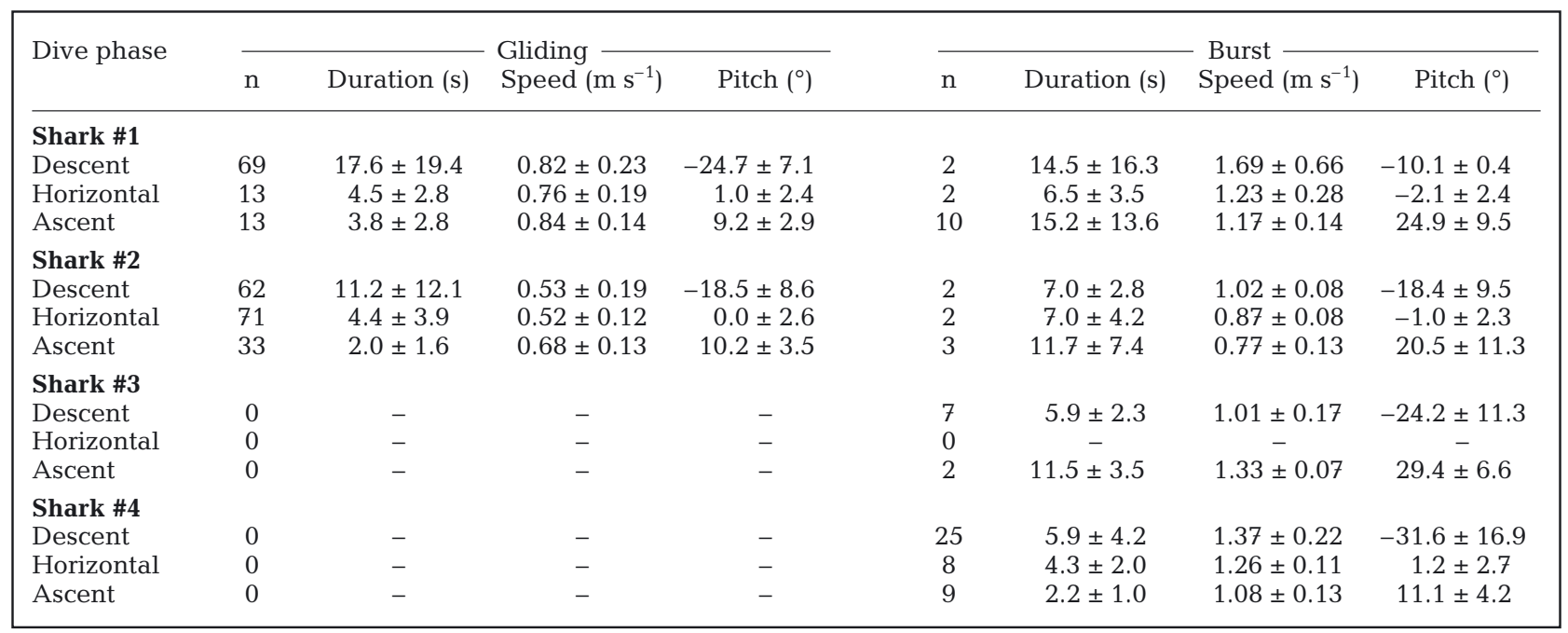

ated with it (Fig. 4). Potential prey items (i.e. reef fishes, pelagic fishes) were observed in 151 images from shark \#3 and 62 images from shark \#4. Not all burst swimming events were related to the presence of prey items (Fig. 4). In a series of 20 min images obtained from shark \#3, a group of mackerel scad Decapterus macarellus was visible, with possible escape be- havior observed in several cases (Fig. 7A). In 5 images, a remora could be seen attached to the back of the shark or swimming close to it (Fig. 7B). In one image, we observed possible successful foraging, with shark \#3 having captured a unicornfish (Fig. 7C). Shark \#4 sometimes encountered schools of potential prey fishes near the seabed below the thermocline (Fig. 7D). 


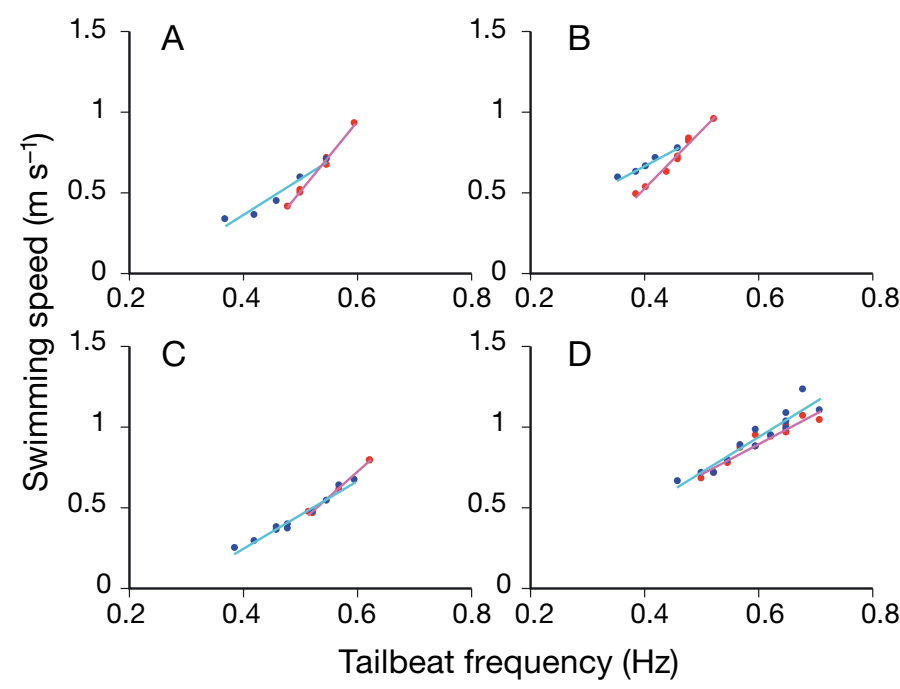

Fig. 6. Galeocerdo cuvier. Relationship between swimming speed and tailbeat frequency for each individual. Blue and red markers show descent and ascent phases, respectively. Lightblue and pink lines are regression lines for descending and ascending, respectively. (A) shark \#1, (B) shark \#2, (C) shark \#3,

(D) shark \#4

\section{DISCUSSION}

Many pelagic fishes exhibit yo-yo diving behavior (Holland et al. 1990, 1999, Brill et al. 1999, Heithaus et al. 2002, Klimley et al. 2002). A variety of hypotheses have been postulated to explain these vertical patterns, including energetically efficient swimming, behavioral thermoregulation, foraging behavior and navigation (Carey \& Scharold 1990, Klimley 1993, Holland et al. 1992, Heithaus et al. 2002, Klimley et al. 2002). In a previous study, yo-yo diving behavior was observed in tiger sharks actively tracked for over $50 \mathrm{~h}$ (Holland et al. 1999), and satellite-tagged for up to several months (Meyer et al. 2010). Although our deployments were short $(<6 \mathrm{~h})$, the swimming pattern observed in this study was essentially the same as those reported in these previous studies, indicating that this behavior was not caused by capture and handling. Deployment of accelerometers on fishes has provided detailed new insights into their activities (Tanaka et al. 2001, Kawabe et al. 2004, Gleiss et al. 2009a,b, Whitney et al. 2010). In this study, we used accelerometers to quan-
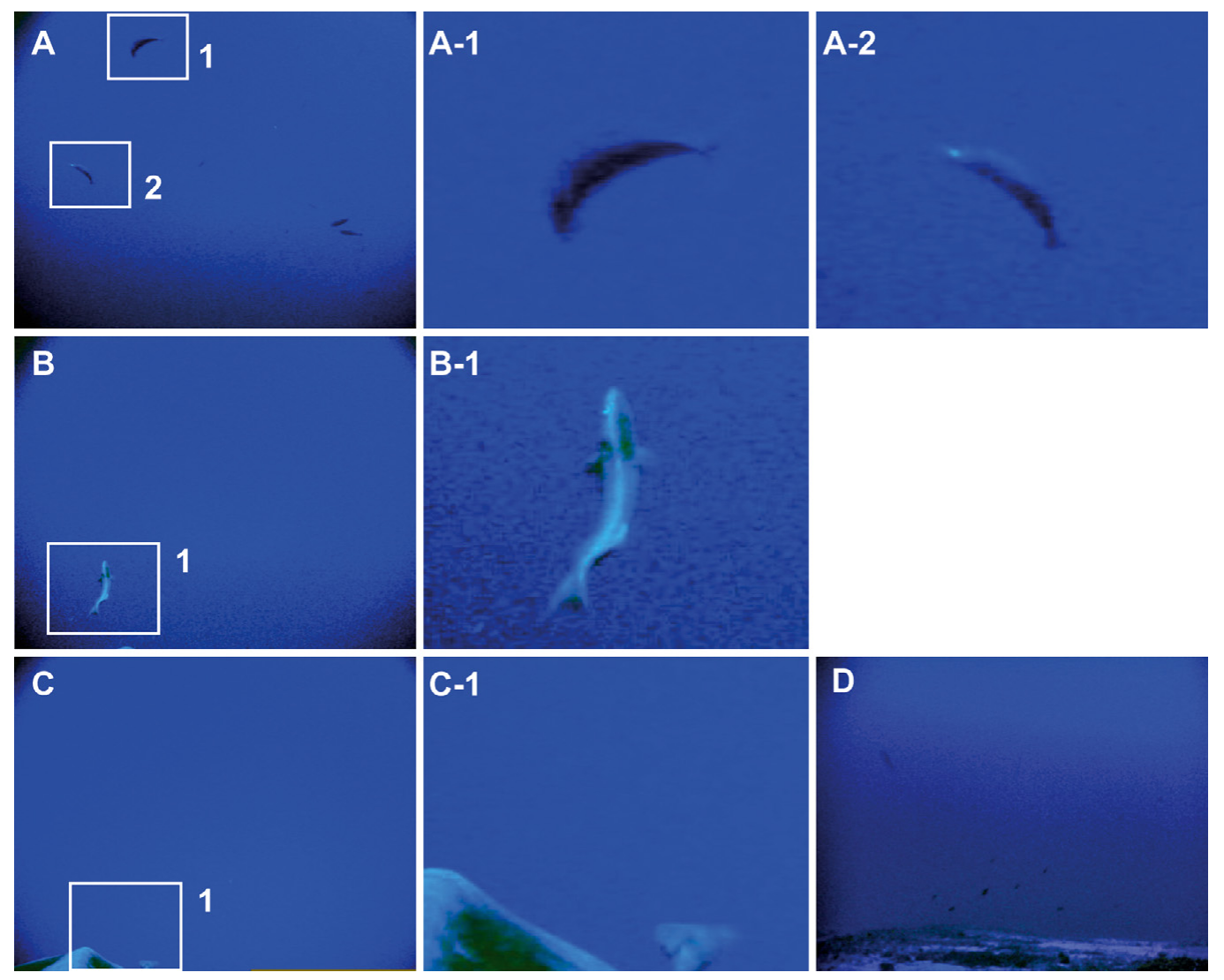

Fig. 7. Images of potential prey items and commensalists (remoras) obtained from shark \#3 (A to C) and shark \#4 (D). Numbered images are magnified views of white squares in the lettered images. In (A), shark \#3 is swimming in a school of mackerel scad Decapterus macarellus with possible fleeing behavior seen. In (B), a remora Remora sp. is swimming close to the surface of the shark. In (C) a unicornfish Naso sp. tail is seen projecting from the shark's mouth, indicating possible successful prey capture. In (D), shark \#4 is swimming near the seabed and potential prey items are seen 
tify fine-scale swimming behavior of tiger sharks, associated with yo-yo diving behavior.

Weihs (1973) predicted that negatively buoyant fish could save energy by using prolonged powerless gliding while descending. Tiger sharks are negatively buoyant, providing an energetic advantage during descents, but increased workload during ascents. We found that tiger sharks had a lower swimming speed at a given tailbeat frequency during ascents than during descents, which is consistent with their negative buoyancy. However, we observed powered swimming dominating descents in all 4 tiger sharks, whereas gliding behavior was seen only sporadically in 2 sharks and accounted for only a minor component $(<18 \%)$ of descents. In addition, sharks covered only relatively short horizontal distances during periods of gliding. Sharks \#1 and \#2 glided for $889 \mathrm{~m}$ and $450 \mathrm{~m}$, respectively, corresponding to only 6.6 and $4.9 \%$ of total horizontal distance traveled during tracking. Weihs (1973) also noted that to save energy, fish would be expected to have shallower pitch angles during gliding than during powered ascent. This theoretical energysaving pattern is closely matched by Japanese flounders Paralichthys olivaceus, which, during migration, utilize powerless gliding while descending and also exhibit a shallow gliding angle $\left(-5.8^{\circ}\right.$; Kawabe et al. 2004, Takagi et al. 2010). In contrast, tiger sharks showed relatively steep (up to $-18^{\circ}$ ) mean gliding angles during descent. Tiger shark diving patterns are broadly consistent with those previously described for blue sharks Prionace glauca, which utilize active downward swimming accompanied by steep gliding descents (Scharold 1989). Powered swimming during descent, together with infrequent gliding at steep angles, suggests that energy saving is not the primary explanation of yo-yo diving by tiger sharks.

Three tiger sharks (sharks \#1, \#2 and \#3) made occasional excursions below $100 \mathrm{~m}$, but most of their vertical movements were confined to the mixed layer (from 0 to $100 \mathrm{~m}$ ). Only shark \#4 swam below the mixed layer - for about half of the tracking time - and occasionally ascended into the mixed layer. Endothermal tuna move back and forth through the thermocline (foraging in cold water below the thermocline and rewarming in the mixed layer) thus behaviorally regulating body temperature (Holland et al. 1992). Similarly, ectothermal blue sharks and ocean sunfish remain in warm surface waters after excursions to cold, deep water (Carey \& Scharold 1990, Cartamil \& Lowe 2004). Therefore, the occasional ascents in shark \#4 might represent behavioral thermoregulation. However, because the other sharks made vertical oscillations within the mixed layer, it is unlikely that the main function of their vertical movements is behavioral thermoregulation.
The combined deployment of digital cameras and accelerometers provided possible evidence of foraging behavior by tiger sharks. For example, shark \#3 accelerated from the seabed towards a school of pelagic fishes. A series of subsequent images revealed that this shark remained close to a school of pelagic fishes for over $20 \mathrm{~min}$, and that fishes appeared to be fleeing (Fig. 7A). Furthermore, in one picture, the shark apparently succeeded in capturing a fish (Fig. 7C). Burst swimming, which might indicate prey pursuit, occurred during all phases of vertical movements. Fishes with swimbladders may be vertically restricted in their movements because of the need to avoid traumatic over-inflation of their swimbladders (Watanabe et al. 2008). The absence of a swimbladder enables sharks to move vertically without a change in buoyancy, which may facilitate prey pursuit.

Tiger sharks are generalist predators, consuming a wide variety of prey, which may include benthic, pelagic and air-breathing animals (Lowe et al. 1996). Tiger sharks also have large home ranges, moving hundreds or thousands of kilometers between oceanic islands and out into open ocean to fill their resource needs (Holland et al. 1999, Meyer et al. 2009, 2010). We know from diet studies and fishing surveys that tiger sharks forage over a wide vertical range from the surface to depths of hundreds of meters (Lowe et al. 1996, Papastamatiou et al. 2006). Optimal foraging theory (e.g. Bres 1993) suggests that generalist feeders should use number maximization foraging strategies, which, in the case of tiger sharks, may include utilizing 3dimensional search strategies to maximize encounter rates with prey distributed patchily throughout the water column. Additionally, navigation via the geomagnetic field may be a potential motivation for yo-yo diving. Elasmobranch fishes have well developed electric and magnetic senses that may be used to detect geomagnetic intensity (Kalmijn 1982). It has been postulated that scalloped hammerhead sharks Sphyrna leweni and blue sharks might decide their swimming course by moving through a water column vertically to sample local magnetic gradients (Carey \& Scharold 1990, Klimley 1993). Since the sharks showed directional swimming in this study, the possibility of navigation-related vertical movements cannot be ruled out.

In conclusion, we showed that the 4 tiger sharks in this study rarely glide during descent, suggesting that their yo-yo diving behavior is not an energy conservation strategy. A combination of accelerometer and image data revealed burst swimming events and possible pursuit and capture of prey during vertical movements. Collectively these results suggest that yo-yo diving by tiger sharks might be an optimal search strategy enabling them to effectively comb large 3dimensional spaces for prey. 
Acknowledgements. This study was supported by the BioLogging Science of the University of Tokyo (UTBLS), led by N. Miyazaki; by Grants-in-Aid for Scientific Research from the Japan Society for the Promotion of Science (A19255001 and 21681002); and by a grant/cooperative agreement from the National Oceanic and Atmospheric Administration, Project 41.R/FM-28PD. The latter is sponsored by the University of Hawaii Sea Grant College Program, SOEST, under Institutional Grant No. NA05OAR4171048 from the NOAA Office of Sea Grant, US Department of Commerce. The views expressed herein do not necessarily reflect the views of NOAA or any of its subagencies, UNIHI-SEAGRANT-JC-0821. We are grateful to the Hawaii Division of Aquatic Resources and Kona Blue Water Farms for providing logistical support. We thank T. Clark and A. Stankus for assisting with fieldwork.

\section{LITERATURE CITED}

Block BA, Dewar H, Blackwell SB, Williams TD and others (2001) Migratory movements, depth preferences, and thermal biology of Atlantic bluefin tuna. Science 293: 1310-1314

Bres M (1993) The behaviour of sharks. Rev Fish Biol Fish 3: 133-159

Brill RW, Block BA, Boggs CH, Bigelow KA, Freund EV, Marcinek DJ (1999) Horizontal movements and depth distribution of large adult yellowfin tuna (Thunnus albacares) near the Hawaiian Islands, recorded using ultrasonic telemetry: implications for the physiological ecology of pelagic fishes. Mar Biol 133:395-408

Carey FG, Scharold JV (1990) Movements of blue sharks (Prionace glauca) in depth and course. Mar Biol 106:329-342

Cartamil DP, Lowe CG (2004) Diel movement patterns of ocean sunfish Mola mola off southern California. Mar Ecol Prog Ser 266:245-253

Gleiss AC, Gruber SH, Wilson RP (2009a) Multi-channel datalogging: towards determination of behaviour and metabolic rate in free-swimming sharks. Rev Methods Technol Fish Biol Fish 9:211-228

Gleiss AC, Norman B, Liebsch N, Francis C, Wilson RP (2009b) A new prospect for tagging large free-swimming sharks with motion-sensitive data-loggers. Fish Res 97:11-16

Heithaus MR, Marshall GJ, Buhleier BM, Dill ML (2001) Employing Crittercam to study habitat use and behavior of large sharks. Mar Ecol Prog Ser 209:307-310

> Heithaus M, Dill LM, Marshall GJ, Buhleier B (2002) Habitat use and foraging behavior of tiger sharks (Galeocerdo cuvier) in a seagrass ecosystem. Mar Biol 140:237-248

Holland KN, Brill RW, Chang RCK (1990) Horizontal and vertical movements of yellowfin and bigeye tuna associated with fish aggregating devices. Fish Bull 88:493-507

Holland KN, Brill RW, Chang RKC, Sibert JR, Fournier DA (1992) Physiological and behavioural thermoregulation in bigeye tuna (Thunnus obesus). Nature 358:410-412

Holland KN, Wetherbee BM, Lowe CG, Meyer CG (1999) Movements of tiger sharks (Galeocerdo cuvier) in coastal Hawaiian waters. Mar Biol 134:665-673

Kalmijn AJ (1982) Electric and magnetic field detection in elasmobranch fishes. Science 218:916-918

Kawabe R, Naito Y, Sato K, Miyashita K, Yamashita N (2004) Direct measurement of the swimming speed, tailbeat, and body angle of Japanese flounder (Paralichthys olivaceus). ICES J Mar Sci 61:1080-1087

Klimley AP (1993) Highly directional swimming by scalloped hammerhead sharks, Sphyrna lewini, and subsurface irra- diance, temperature, bathymetry, and geomagnetic field. Mar Biol 117:1-22

Klimley AP, Beavers SC, Curtis TH, Jorgensen SJ (2002) Movements and swimming behavior of three species of sharks in La Jolla Canyon, California. Environ Biol Fishes 63:117-135

> Lowe CG, Wetherbee BM, Crow GL, Tester AL (1996) Ontogenetic dietary shifts and feeding behavior of the tiger shark, Galeocerdo cuvier, in Hawaiian waters. Environ Biol Fishes 47:203-211

Marshall GJ (1998) Crittercam: an animal-borne imaging and data logging system. Mar Technol Soc J 32:11-17

> Meyer CG, Clark TB, Papastamatiou YP, Whitney NM, Holland KN (2009) Long-term movement patterns of tiger sharks Galeocerdo cuvier in Hawaii. Mar Ecol Prog Ser 381:223-235

Meyer CG, Papastamatiou YP, Holland KN (2010) A multiple instrument approach to quantifying the movement patterns and habitat use of tiger (Galeocerdo cuvier) and Galapagos sharks (Carcharhinus galapagensis) at French Frigate Shoals, Hawaii. Mar Biol 157:1857-1868

Papastamatiou YP, Wetherbee BM, Lowe CG, Crow GL (2006) Distribution and diet of four species of carcharhinid shark in the Hawaiian islands: evidence for resource partitioning and competitive exclusion. Mar Ecol Prog Ser 320: $239-251$

Sakamoto KQ, Sato K, Ishizuka M, Watanuki Y, Takahashi A, Daunt F, Wanless S (2009) Can ethograms be automatically generated using body acceleration data from freeranging birds? PLoS ONE 4(4):e5379

Sato K, Mitani Y, Cameron MF, Siniff DB, Naito Y (2003) Factors affecting stroking patterns and body angle in diving Weddell seals under natural conditions. J Exp Biol 206: 1461-1470

Sato K, Watanuki Y, Takahashi A, Miller PJO and others (2007) Stroke frequency, but not swimming speed, is related to body size in free-ranging seabirds, pinnipeds and cetaceans. Proc Biol Sci 274:471-477

Scharold JV (1989) Swimming behavior and energetics of sharks. PhD dissertation, Massachusetts Institute of Technology, Cambridge, MA

Sims DW, Southall EJ, Humphries NE, Hays GC and others (2008) Scaling laws of marine predator search behaviour. Nature 451:1098-1103

Takagi T, Kawabe R, Yoshino H, Naito Y (2010) Functional morphology of the flounder allows stable and efficient gliding: an integrated analysis of swimming behaviour. Aquat Biol 9:149-153

Tanaka H, Takagi Y, Naito Y (2001) Swimming speeds and buoyancy compensation of migrating adult chum salmon Oncorhynchus keta revealed by speed/depth/acceleration data logger. J Exp Biol 204:3895-3904

> Wada Y, Kashiwagi N (1990) Selecting statistical models with information statistics. J Dairy Sci 73:3575-3582

- Watanabe Y, Mitani Y, Sato K, Cameron MF, Naito Y (2003) Dive depths of Weddell seals in relation to vertical prey distribution as estimated by image data. Mar Ecol Prog Ser 252:283-288

> Watanabe Y, Baranov EA, Sato K, Naito Y, Miyazaki N (2004) Foraging tactics of Baikal seals differ between day and night. Mar Ecol Prog Ser 279:283-289

Watanabe Y, Wei Q, Yang D, Chen X and others (2008) Swimming behavior in relation to buoyancy in an open swimbladder fish, the Chinese sturgeon. J Zool 275:381-390

Watanabe YY, Sato K, Watanuki Y, Takahashi A and others (2010) Scaling of swim speed in breath-hold divers. J Anim Ecol 80:57-68 
Weihs D (1973) Mechanically efficient swimming techniques for fish with negative buoyancy. J Mar Res 31: 194-209

Whitney NM, Pratt HL Jr, Pratt TC, Carrier JC (2010) Identifying shark mating behaviour using three-dimensional

Editorial responsibility: Hans Heinrich Janssen, Oldendorf/Luhe, Germany acceleration loggers. Endang Species Res 10:71-82

Yoda K, Sato K, Niizuma Y, Kurita M, Bost CA, Le Maho Y, Naito Y (2001) A new technique for monitoring the behaviour of free-ranging Adélie penguins. J Exp Biol 204: $685-690$

Submitted: August 30, 2010; Accepted: December 6, 2010

Proofs received from author(s): February 23, 2011 